$<$ Book Info > Chimpanzees of the Lakeshore: Natural History and Culture at Mahale By Toshisada Nishida

$\operatorname{AUTHOR}(\mathrm{S})$ :

\title{
CITATION:
}

<Book Info> Chimpanzees of the Lakeshore: Natural History and Culture at Mahale By Toshisada Nishida. Pan Africa News 2011, 18(2): 26-26

ISSUE DATE:

2011-12

URL:

http://hdl.handle.net/2433/152158

RIGHT:

Copyright (C) Pan Africa News. 
<NEWS>

\section{Memorial Service for the Late Professor Toshisada Nishida}

The memorial service for Professor Toshisada Nishida who passed away on 7 June 2011, was held at Kyoto University and the Westin Miyako Hotel Kyoto, Japan, on 2 October 2011.

It started at three in the afternoon and was attended by more than 200 people including the colleagues, friends and students of the deceased. A brief note of his career and a copy of Pan Africa News, Special Issue Commemorating the late Professor Nishida, were given to each participant.

At a lecture hall at the Graduate School of Science, Kyoto University, Drs. Masao Kawai, Kosei Izawa, Ryutaro Ohtsuka, William McGrew, Miho Nakamura, and Kazuhiko Hosaka gave talks about Prof. Nishida's memories in different time periods. Then the video messages from his international colleagues (Drs. Richard W. Wrangham, John C. Mitani, Frans B. M. de Waal) and from Tongwe assistants were shown with Japanese subtitles. The final speaker at this hall was Ms. Ikuko Nishida, the bereaved daughter. She shared her memories of her father at home. Each speech was really warm and reminiscent of Professor Nishida's frank character.

At six in the evening, the participants moved by bus to a hall of Westin Miyako Hotel Kyoto, and offered flowers to the altar. Dr. Akisato Nishimura made a short speech and gave a toast to the memory of Professor Nishida. Photos, videos, and some other articles left behind were exhibited at the hall. Participants watched them and cherished the memory of the deceased with other participants. Finally, Mrs. Haruko Nishida, the bereaved wife, made an acknowledgment to close the service at eight in the evening.

Several people kindly made donations for this service. The remaining balance will be donated to the Mahale Wildlife Conservation Society. We would like to continue our activities by following the deceased's will to conserve chimpanzees and to promote the welfare and education of Tongwe people who have cooperated with the long-term research at Mahale.

\section{<BOOK INFO>}

\section{Chimpanzees of the Lakeshore: Natural History and Culture at Mahale}

\section{By Toshisada Nishida}

Chimpanzees are humanity's closest living relations and are of enduring interest to a range of sciences, from anthropology to zoology. In the West, many know of the pioneering work of Jane Goodall, whose studies of these apes at Gombe in Tanzania are justly famous. Less well- known, but equally important, are the studies carried out by Toshisada Nishida on the eastern shore of Lake Tanganyika. Comparison between the two sites yields both notable similarities and startling contrasts. Nishida has written a comprehensive synthesis of his work on the behaviour and ecology of the chimpanzees of the Mahale Mountains. With topics ranging from individual development to population-specific behavioural patterns, it reveals the complexity of social life, from male struggles for dominant status to female travails in raising offspring. Richly illustrated, the author blends anecdotes with powerful data to explore the fascinating world of the chimpanzees of the lakeshore.
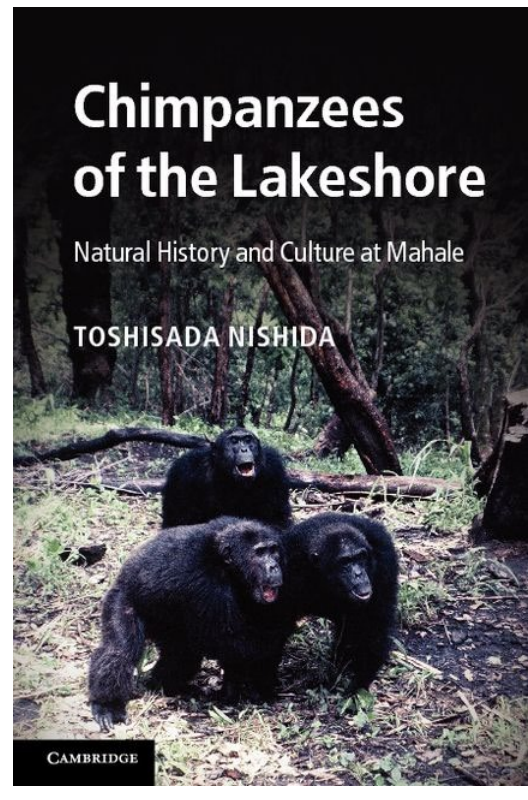

340 pages

Cambridge University Press

Publication date: December 2011

Paperback \$50.00; Hardcover \$125.00

ISBN: 9781107601789 (P), $9781107015784(\mathrm{H})$

\section{Contents}

Foreword Frans de Waal; Preface; Introduction; 1. At the beginning; 2. Food and feeding behaviour; 3. Growth and development; 4. Play and exploration; 5. Communication as culture; 6. Female life histories; 7. Sexual strategies; 8. Male political strategies; 9. Culture; 10. Conservation and the future; Postscript; Acknowledgements; References; Index.

Pan Africa News, Vol. 18, No.2

Published in December, 2011

Address: c/o Human Evolution Studies,

Dept. of Zoology, Faculty of Science, Kyoto Univ., Kyoto, 606-8502, JAPAN

TEL: $(+81) 75-753-4093$

FAX: $(+81) 75-753-4115$

E-mail: pan.editor@gmail.com

URL: http://mahale.main.jp/PAN/

ISSN: 1884-751X (Print), 1884-7528 (Online) 